\title{
Technology-Based Collaborative Learning for Developing the Dynamic Concept of the Angle
}

\author{
Nimer Baya'a ${ }^{1 *}$, Wajeeh Daher ${ }^{1}$, Samah Mahagna ${ }^{1}$ \\ ${ }^{I}$ Al-Qasemi Academic College of Education, P.O. Box 124, Baqa-El-Gharbia 3010000, Israel.
}

\begin{abstract}
This research intends to investigate the effect of collaborative computerized learning using GeoGebra on the development of the concept images of angle among seventh graders who were engaged in computerized collaborative activities that encouraged the development of five types of angle concept images: verbal, authentic-life, graphical, numeric, and dynamic. The research sample consisted of eight seventh grade students who worked collaboratively in groups of two Two tests (a pre-test and a post-test) were administered to examine the development of students conceptual images of the angle. In addition, interviews were held with the participants to study this development. The Constant Comparison Method was used to analyze the data. The results showed positive effects of the visual and dynamic use of GeoGebra, as well as of the collaborative learning, on the development of participants' concept images of the angle, especially the dynamic one. The research results point to the importance of integrating dynamic tools into the teaching and learning of mathematics.
\end{abstract}

\author{
Keywords: \\ Angle; Dynamic Concept; \\ Collaborative Learning; \\ Computerized Learning; \\ Technological Environment; \\ GeoGebra; Mathematics.

$\begin{array}{llll}\text { Article History: } & & \\ \text { Received: } & 04 & \text { July } & 2021 \\ \text { Revised: } & 25 & \text { October } & 2021 \\ \text { Accepted: } & 09 & \text { December } & 2021 \\ \text { Published: } & 01 & \text { February } & 2022\end{array}$

\section{1- Introduction}

The topic of angles is a main topic in school geometry. Students need to understand adequately concepts related to angles in order to further their study of geometric concepts and relations. In any other case, students' cognitive understanding of subsequent topics in geometry in particular and daily life activities connected with geometric concepts in general will be negatively affected [1]. Moreover, the concept of angle will never be fully grasped until students can identify and distinguish it easily, and consequently; use it better in their life. This can be achieved through dynamic manipulation of the angle by using technological tools such as GeoGebra, Applets, etc. This would promote and facilitate learning geometric concepts and relations. Once technology is used properly, the learning environment becomes suitable for students' engagement [2] and for visual and dynamic investigations, through which students will grasp conceptually geometric topics [3]. In the present research, we investigate how GeoGebra helps seventh grade students develop the concept of angle through their use of dynamic objects enabled in tools like GeoGebra.

In addition to the use of technological tools that promote students' investigations of mathematical concepts [4, 5], collaborative learning encourages students to participate in investigating mathematical concepts, argue with each other regarding these concepts, and raise questions for discussion. This would result in internal sharing of mathematical concepts [6] through seeing the relations between these concepts and other concepts already known to the students. Furthermore, during collaborative investigation, misconceptions are raised for discussion among the students and between them and their teacher, which results in correcting these misconceptions [7]. This is preferable to getting the right answers directly as a condition for conceiving the mathematical concept definitions.

\footnotetext{
*CONTACT: bayaan@qsm.ac.il
}

DOI: http://dx.doi.org/10.28991/ESJ-2022-06-01-09

(C) 2022 by the authors. Licensee ESJ, Italy. This is an open access article under the terms and conditions of the Creative Commons Attribution (CC-BY) license (https://creativecommons.org/licenses/by/4.0/). 
Following, we present the literature review related to the topic of the article - concept image in general and concept image of the angle. Then, we present the methodology that served us in investigating students' concept images of the angle and the development of this concept image. Afterwards, we present the students' concept images of the angles, before and after the experiment, and comment on the development of their concept images as a result of the experiment. We then discuss the development of the participating students' concept image of the angle, where we show the influence of the dynamic technology on this development. Doing so, we refer to previous research.

\section{1-1- Concept Image}

A concept image refers to the total cognitive structures that are associated with the concept and includes all the concept images of the learner, as well as the associated properties and processes which have been built up over the years through different experiences. Concept images are likely to change depending on the different stimuli the individual experiences [8]. It is possible for the concept image to be very different from the formal concept, which is scientifically acceptable. This difference may lead to the emergence of cognitive conflict [9]. Vinner and Dreyfus [10] stated that students divide concepts into definition and concept images, without relating properly the formal definition to the concept images they hold.

The concept image develops based on the ideas learnt by students at different stages. More specifically, they change according to students' experiences, examples they have, and their awareness of mathematical concepts [10, 11]. This possibility of change made researchers suggest to let students experience a comprehensive study of the mathematical concepts or relation in order to improve them when needed [12]. In addition, Concept images can be incarnated into verbal forms; however, these verbal forms are not the first thing that stimulates students' memories [13].

\section{1-2- The Concept Image of Angle}

When students utilize technology to investigate mathematical concepts, they are introduced to new experiences and various examples that communicate these concepts dynamically with different forms and different representations. Consequently, technological tools such as GeoGebra are cognitive tools that accompany students in developing multiple concept images associated with mathematical concepts [14-16]. Among these concept images is the dynamic representation of the mathematical concepts. Mathematical curricula usually lack dynamic representation of the angle concept, which is normally seen as a fixed entity by students. For instance, some students do not realize what happens to the angle after rotating or extending one of its rays.

Moreover, most mathematical curricula concentrate on four concept images of the angle: verbal, authentic-life, graphical and numeric. Therefore, the teaching unit that we built to develop the various concept images of the angle took in consideration also the dynamic concept image of the angle, hoping to develop the students' conceiving of this concept image. There is no doubt that the concept of angle is multifaceted, therefore, researchers had given different definitions for this concept [17]. These definitions include the rotation of a ray around its endpoint, the geometrical shape formed when two rays meet at their endpoints, the area enclosed between two rays that meet in one endpoint, etc. For this reason, students may have a set of different images associated with the concept of angle.

Clements \& Battista (1992) [18] and Mitchelmore \& White (2000) [19], pointed out that students do not realize the angle as a rotation of a ray, therefore, their perception of the concept is partial peripheral. Mitchelmore \& White (2000) [19] conducted a study to identify the way students from grades (2-8) define the angle concept. They found that the students looked at an angle as a point and two arms. Many students in the eighth grade still do not relate rotation to the concept of angle, what results in wrong perception of the angle concept, as believing that the length of the angle arms affects its value. Several studies showed that technology helps represent the angle dynamically [20], which enables students to notice the rotation of the ray, and how this rotation affects the measure of the angle [14-16, 21]. The authors of the current study reviewed the mathematics curriculum of the seventh grade in Israel, and they found that this curriculum presents four different types of representations of the angle concept: verbal, authentic-life, graphical and numeric. In more detail, according to this curriculum, the seventh grade students should possess different meanings related to angles including: defining and representing angles verbally, representing angles in daily life experiences, drawing angles and measuring angles. This study focused on the development of the angle notion and representations among seventh grade students after carrying out a number of collaborative activities in a computerized environment.

\section{1-3-Research Question}

What is the effect of computerized collaborative learning based on GeoGebra on the development of concept images of the angle concept among seventh graders?

\section{2- Research Methodology}

\section{2-1-The Research Procedure, Context and Participants}

The participants consisted of eight female seventh graders (12-13 years old) who studied in a middle school of middle socio-economic status. The students in the particular seventh grade were of various levels including weak, good, and 
excellent students. The participants in the present research were grouped into four pairs. A pre-test and a post-test were built to measure the development of the different types of representations of angle concept including: the verbal, the authentic life, the graphical, the numeric and the dynamic. After teaching the unit, the students were interviewed individually in order to identify the development of their angle concept images.

Following, we present the research instruments, and the research analysis tools. Doing that, we utilize Tables that illustrate these instruments and analysis tools, which makes them clearer to the reader.

\section{2-2-The Research Instruments}

A pre-test and a post-test were administered to identify the concept images of angle among seventh graders. The authors built the pre-test and the post-test based on the angle ideas in the Israeli mathematics book for Grade six. According to this curriculum, the sixth-grade students should possess different notions related to angles including: Defining and representing angles verbally, representing angles in daily life experiences, drawing angles and measuring and calculating angles. The teaching unit developed included also the dynamic image of angles. The students took the pre-test before carrying out the collaborative computerized activities included in the teaching unit. Later, they took another test (a post-test), where the results of the two tests were compared to arrive at the development of students' concept images in the five representations. Table 1 shows examples of concept images associated with some representations of the angle.

Table 1. Examples of concept images of various angle perceptions

Concept Images
Verbal concept images:
For example, for the student to say: door opening, book opening, room corner.
Graphical concept images:

\begin{tabular}{l} 
Verbal concept images: \\
- Two rays starting from the same point and are called angle legs. \\
- Part of the plane determined by two rays. \\
- Degree of rotation. \\
\hline Graphical concept images: \\
Verbal concept images, such as: \\
- Measuring the angle with a protractor. \\
- The angle value.
\end{tabular}




\section{2-3- Data Analysis Method}

The Constant Comparison Method was used to obtain various themes related to the manifestation of the five representations of the angle: verbal, authentic-life, graphical, numeric and dynamic. Then, the participating students' concept images of the angle manifested in the post-test were compared with those in the pre-test. Table 2 shows an example of the analysis taken from the pre-test, while Table 3 shows an example of the analysis taken from the posttest.

Table 2. Analysis examples of categories taken from the pre-test

\begin{tabular}{|c|c|c|}
\hline Aspect & Category & Examples \\
\hline \multirow{8}{*}{ Daily life } & \multirow{5}{*}{$\begin{array}{l}\text { Representing angle } \\
\text { verbally in daily life as a } \\
\text { right angle }\end{array}$} & - The home table has right angle \\
\hline & & - The angle of an opened window \\
\hline & & - The angle of an opened Door \\
\hline & & - The angle of an opened Closet \\
\hline & & - Folding a sheet of paper using a specific angle \\
\hline & \multicolumn{2}{|l|}{ Graphical representation } \\
\hline & \multirow{2}{*}{$\begin{array}{l}\text { The role of the angle in } \\
\text { daily life }\end{array}$} & - Arranging and organizing \\
\hline & & $\begin{array}{l}\text { - The right angle gives a more beautiful look to } \\
\text { the table / wall - gives beauty for the shape. }\end{array}$ \\
\hline
\end{tabular}

Table 3. Analysis examples of categories taken from the post-test

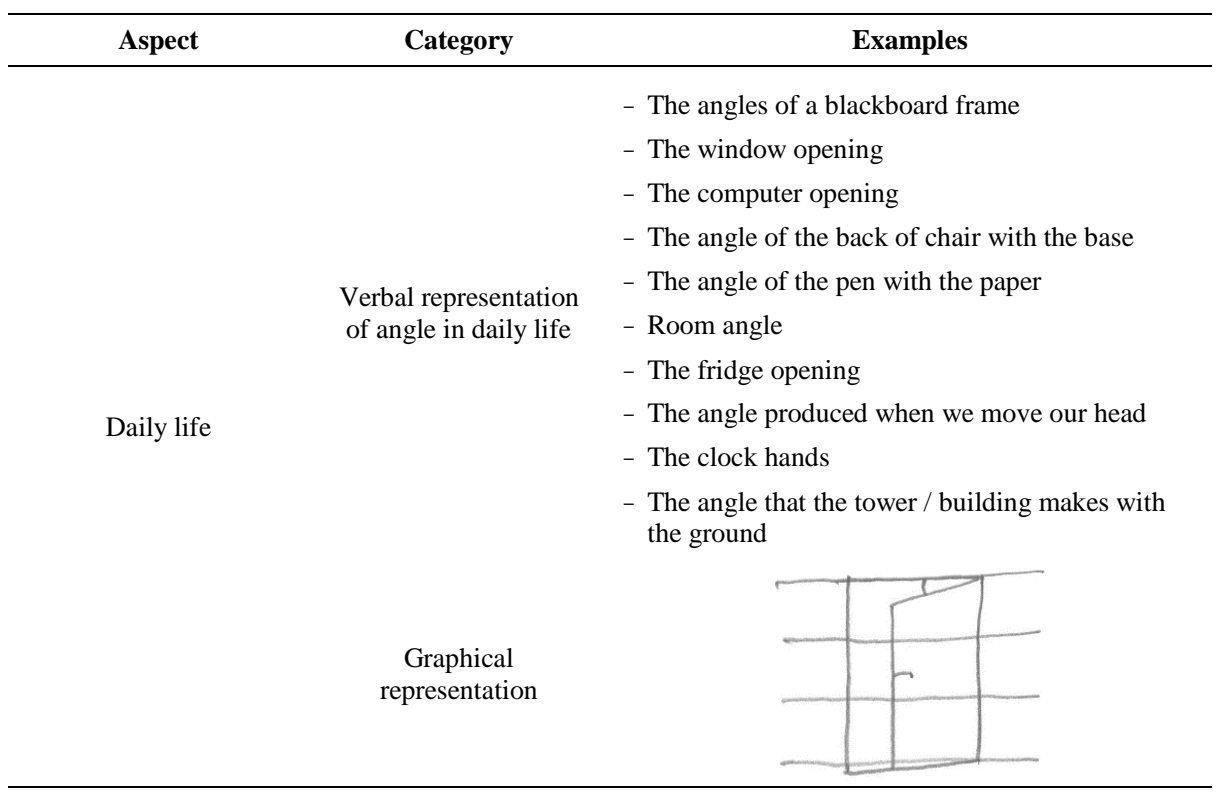

\section{2-4- The Technological Tool}

The tool that the students worked with was GeoGebra. It was developed by Markus Hohenwarter in 2002. GeoGebra is an interactive tool that targets students in the mathematics classroom. It includes different windows, as the Algebra and the Geometry windows [22]. Thus it could be used to assist the learning of various mathematical topics, as function transformations [23] and triangles [24].

We chose GeoGebra for its visual and dynamic features that can assist the students in investigating and discovering independently and collaboratively various mathematical representations of the angle concept and its components. The students were also given the opportunity to construct various angle representations through performing teacher-guided activities. More specifically, we developed a unit that utilizes computerized collaborative learning using GeoGebra and based on Guided Discovery.

\section{2-5-The Teaching Unit}

The unit included seven activities that aim to develop different representations of the angle concept. The activities were based on investigation to help the students discover the different representations of the angle. It also included construction activities to help them construct mathematical objects related to the angle concept in order to understand the angle manifestations. The students were also asked to observe the effect of the dynamic changes on the angle 
representations. The collaborative aspect was also stressed through the instructions in the activities before and during performing the activities. For example, some of the teacher's instructions were:

- When solving a problem, think aloud and describe to your mate the solution steps asking her for help.

- When your mate performs a move in GeoGebra, ask her to explain this move and discuss it with her.

- Discuss together and write a proper definition of the angle.

- Explain this phenomenon to your mate and discuss it with her.

- Discuss, with your mate, the other angles you see in the pyramid, and explain why these are considered angles.

- Construct an angle using an icon in GeoGebra and give your mate a chance to construct other angles herself.

- Raise a conjecture and ask your mate to verify its correctness.

- Formulate a definition of the angle based on the way you constructed it in GeoGebra; then ask your mate to check how exact the definition is, by constructing an angle in GeoGebra using this definition, or constructing an example of a shape which is not an angle but satisfies the conditions of the definition.

\section{3- Research Results}

The main objective of this research was to identify the effect of computerized collaborative learning using GeoGebra on the development of the images of the angle concept among seventh graders. In this section, we shall summarize the development of the students' images of the angle concept due to collaboratively being engaged with the angle concept with the help of GeoGebra.

\section{3-1- Verbal Image}

The research results showed significant development of verbal perception of the ray concept and, consequently, the angle concept. Before the experiment, the students could not define the ray correctly saying that it is the distance between two fixed points. While after the experiment, all the students defined both the ray and the angle correctly based on their graphical manipulation of these concepts in GeoGebra. It was clear that the students' development of the graphical perception of the ray and the angle led to the correct verbal perception of these concepts. For in-stance, the students drew the ray in GeoGebra starting with an endpoint, so they defined it as a straight line, which has an endpoint from one side only.

An example on students' definition of angle before the experiment:

Before the experiment: Two ends of two edges constitute an angle.

An example on students' definition of angle after the experiment:

The angle is the object that results from two rays that have the same end point.

\section{3-2- Authentic-Life Image}

During the experiment, the students developed various meanings of the authentic-life representation of the angle. For instance, before the experiment, the students expressed the angle in daily life only verbally as the corner of a door, a window, or cover of an open book. They also talked only about right angles in daily life and did not mention any dynamic ones. However, the students, after the experiment, had developed deeper understanding of the angle concept to the extent that they started to talk about different types of angles in daily life both verbally and graphically. For instance, they began to talk about and draw angles formed by an open window, the angle made by the back and the base of a chair, the angle formed between the pen and the sheet of paper, the angle of an open fridge door, the angle of an open laptop, the angle formed by the hands of a clock, or the viewing angle formed by the observer's eye when looking at an object (for example: a building).

\section{An example on students' authentic-life representation of angle before the experiment:}

The angle is a corner of the door when it is opened.

An example on students' authentic-life representation of angle after the experiment:

The angle could be the corner of the door whether it is opened or closed.

Furthermore, the students developed wide perception of the angle concept as a dynamic one that can be moved and controlled based on their daily needs. For instance, the angles formed when they open a laptop, when they move a pen on a sheet of paper, when they move their heads, also angles formed by the movement of the hands of a clock, or viewing angle formed by the observer's eye when looking at an object. They could notice the change in the angle's value according to the movement of its sides or its vertex as in the viewing angle case. The study also showed that prior to the experiment, the students mentioned only two important aspects of angles role in daily life: beauty and organization. Yet after the experiment, the students listed four further important aspects in performing daily tasks: household chores, practicing 
sports and writing and reading. All in all, the development the students had with respect to the angle concept resulted in developing students' perception of its vital roles in their daily lives.

An example on students' perception of angle role in daily life before the experiment:

The angle gives beauty to everyday life.

An example on students' perception of angle role in daily life after the experiment:

The angle has vital role in our everyday life.

\section{3-3- Graphical Image}

There was a noticeable development in students' abilities to perceive graphically the angle concept. For example, the participants mentioned only three types of angles before the experiment (acute, obtuse and right). Furthermore, the students were not able to draw all three types of angles in one geometrical shape. However, after using GeoGebra, and through collaborative leaning, the students stated five different types of angles (acute, obtuse, right, straight and reflex) and managed to draw all of them using one geometrical shape.

An example on students' graphical perception of angle before the experiment:

The angle is of three types: acute, right and obtuse.

An example on students' graphical perception of angle after the experiment:

The angle is a rotation. This rotation could be positive or negative. It could be less than 360 degrees or more.

\section{3-4- Numeric Image}

Before the experiment, the students stated that shrinking or extending the side of an angle affects its value considerably; yet after the experiment, the students denied this claim and stated that the change in the length of the angle sides does not affect its value, because angles are formed by rotating a ray, and the lengthening or shortening of that ray does not affect the size of the angle formed by its rotation.

An example on students' perception of angle size before the experiment:

When we extend the rays of an angle, its measure increases because it turns to have more space inside it.

An example on students' perception of angle size after the experiment:

When we extend the rays of an angle, nothing happens to its measure. Nothing changes here though it seems that the space inside it increases. In fact, its rays are infinite in one direction.

\section{3-5- Dynamic Image}

The students of the seventh grade were not capable of dealing with the problems related to the dynamic perception of angles on the pre-test. For example, they could not imagine the effect of moving one of the angle's components such as the vertex or a side on the angle's value. After the experiment, the students managed to overcome problems of this type on the post-test to the extent that they provided valid verbal and graphical justifications for most of them based mainly on the idea that an angle is a rotation of a ray.

After carrying out the activities, the students stressed, during the interviews, that before using GeoGebra it was very difficult for them to imagine what happens to the angle when they stretch or shrink one of its sides or move its side or its vertex. On the other hand, when they started to use it, they were able to imagine every possible change that might happen when moving any part of the angle. Therefore, they began to realize the importance of angles in their daily lives and how dynamic they are. For example, they started noticing the change in the value of the viewing angle of a particular object to the observer's eye when approaching or moving away from it, or the change in the value and the shape of the angle when a laptop screen is moved in order to use it in a comfortable position and to see the objects on the screen properly.

An example on students' dynamic perception of angle before the experiment:

There is one size for each angle. Angles with different sizes are different.

An example on students' dynamic perception of angle after the experiment:

Different angles can result from one original angle. These could result from rotating a ray of an angle around the second ray.

\section{4- Discussion}

The study results showed that using computerized collaborative environment helped students develop their images of the angle concept, mainly the dynamic and daily-life images. Before the experiment, these students managed to express the angle concept mainly verbally, considered only right angles and did not view angles as dynamic objects. 
This indicates that the participants had partial perception of the angle, which was reflected also in the examples they gave in the pre-test. After working visually, dynamically and collaboratively with angles, we notice that the students' perception of angles got more profound through expressing various kinds of angles from their daily life verbally, graphically and dynamically. This advancement achieves one of the objectives of the Principles and Standards for School Mathematics [25], which emphasizes the importance of linking mathematics with students' daily-life as well as their personal interests. This linking could be accomplished in indoor and outdoor learning environments [26] as well as in the regular classroom or the social networking one [27, 28]. Moreover, the development of students' perception of the angle as dynamic object could be due to the use of the dynamic features of GeoGebra, such as dragging that the students utilized when carrying out the activities. These dynamic features are reported as assisting the learner in building her or his mathematical knowledge [29]. Specifically, for the present research, students' interactions with dynamic objects, in our case angles in GeoGebra, enabled them to see how dragging changed the mathematical object graphically as well as its measures, which allowed the participating students to find characteristics of the angle that might remain hidden in static diagrams of the mathematical object [30]. Moreover, these interactions with dynamic angles constituted strategic use of a content-specific mathematics technology that supported the students in exploring and identifying the mathematical concept with which they worked [31], here, the angle. Thus, the results indicate the importance of the dynamic technology in assisting students to overcome misconceptions expected when learning compound mathematical concepts and relations [32].

With regard to students' graphical images of angles, it is possible to attribute students' development in recognizing various types of angles to several factors including: the construction process using GeoGebra and the dragging process which helped students notice how angles change. Besides, the activities instructions (e.g. moving one side of the angle and identifying the type of the resulted angle) helped the students develop various concept images of the angle. Here, the role of the teacher, as a source of the activities, is critical. The teacher here is seen as escalator of students' knowledge of mathematical objects and relations [30].

In addition, collaboration and discussion helped in increasing students' awareness of various aspects of the angle concept. All these interpretations are consistent with the claim that the concept images of a particular concept are the result of students' experiences, including examples, of this mathematical concept [11, 13]. Furthermore, the teacher's actions and interactions with the students, including the activity instructions, presented her as an orchestrator and coach of the strategic use of GeoGebra for the learning of the angle concept [30].

In terms of the numeric image of angles, the students stated, before the experiment, that the extension or shrinking of the ray of the angle affects the angle's size. After the students' engagement with angles collaboratively utilizing GeoGebra, they noticed that neither the extension nor the shrinking affects the size of the angle, because an angle appears as a consequence of rotating a ray and has nothing to do with the decrease or increase of the two sides of the angle. This development of students' numeric concept of the angle was supported by the software potentiality of measurement that enabled the students to verify their claims and substantiate them [33]. Furthermore, these findings emphasize the claim of Biber et al. [34] who concluded that when students have meaningful, real experiences of measuring and comparing angles via different methods, they become more likely to perceive the standard definition of the angle and understand that the angle value is affected by the amount of the rotation of its ray rather than the length of its sides. For this matter, our study concentrated on the use of technology and the implementation of collaborative learning strategies for treating students' misconceptions of angles.

As far as the dynamic image of the angle is concerned, the students had developed deeper understanding of this image due to the use of GeoGebra in solving the problems in the activities as the students emphasized during the interviews. They stressed that GeoGebra helped them imagine and perceive the angle concept deeper, especially when they realized it as an object resulting from rotating a ray. This development of their dynamic concept of angles depended on working with GeoGebra which helps display ideas and concepts visually and dynamically through various representations that are mostly related to geometry and algebra [25]. Generally speaking, using technology encourages looking at angles as an act of rotating a ray around its endpoint, and thus helps overcome misconceptions related to the angle concept, as well as widens the meanings associated with the mathematical concept [24, 35].

In addition to the arguments above, the research results show the advantages of students' collaboration in groups or pairs. The participating students in the present research were urged to collaborate with and criticize each other through discussions and comments. This collaboration supported the students in carrying out the activities successfully [36-38]. The students managed to define the concepts correctly and gradually based on arguments and constructions [39]. These results show that it is necessary to allow students to construct, explore and investigate mathematical concepts by themselves, as well as to encourage them to develop their knowledge of mathematics through collaboration with each other. The results on the role of collaboration in supporting their mathematical investigations is in line with Beňo [40] who argues that technology supports how people collaborate. In addition, it is in line with studies that showed the positive impact of working in a group on students' learning with technology [41]. 


\section{5- Conclusion and Recommendations}

The multiple visual and dynamic features of GeoGebra proved to be very helpful in collaborative settings in deepening students' understanding of the angle concept as an object that can be moved and controlled. This led to their widening their images of the angle, especially as they realized that different types of angles could be created when a ray is rotated. This dynamic concept of the angle is what the students lacked before the experiment, for they were not able to express the angle created dynamically from rotation. The deficiency of not being able to see the angle as a rotation of a ray was stressed in previous studies, concluding that it led to partial understanding of angles and misconceptions included in the images of students of the angle concept. Here, technology enabled seeing the angle as a rotation, which helped the students develop a new image of the angle, that of rotation. In the context of the present research, technology was one variable of the environment in which the students learned. Another variable was collaboration. Collaboration, with the support of technology, supported the work of the participants. Specifically, collaboration among group members led to lively mathematical discussions about the different images related to the angle concept. These lively mathematical discussions indicate the importance of student-centered learning for supporting students' conceptual learning. These discussions helped reach a concise and accurate definition of what an angle is, and consequently, led to a deep understanding of the various images of the angle concept. The results of the present research agree with the consideration that small-group discussions that involve students and their teacher and that focus on mathematical meanings through problem solving offer great potential for debate and argument. Future research needs to focus on the contribution of technology-based small-group discussions to other aspects of students' learning, such as metacognition and its relationship with the affective components of students' learning.

We recommend that teachers share different examples of angles that take various images, especially the dynamic one. This could be done when teachers encourage students to construct and manipulate angles visually and dynamically in GeoGebra. Teachers need to participate with students in discussing ideas related to angles, after and during students' work with GeoGebra to construct angles collaboratively. This participation helps students arrive at an accurate conceptdefinition of the angle, which is as close as possible to the standard one. A recommendation is made regarding future research as well. In the present research, we were concerned with students' concept images of the angle before working with technology and after it. Future research needs to consider students' processes with technology in addition to their interaction in the presence of technology and how this interaction contributed to the enrichment of their conceptual images of the angle.

\section{6- Declarations}

\section{6-1-Author Contributions}

N.B., W.D., and S.M. contributed to the design and implementation of the research, to the analysis of the results and to the writing of the manuscript. All authors have read and agreed to the published version of the manuscript.

\section{6-2-Data Availability Statement}

The data presented in this study are available on request from the corresponding author.

\section{6-3-Funding}

The authors received no financial support for the research, authorship, and/or publication of this article.

\section{6-4- Ethical Approval}

Participants gave their written consent to use their anonymous data for research purposes.

\section{6-5-Conflicts of Interest}

The authors declare that there is no conflict of interests regarding the publication of this manuscript. In addition, the ethical issues, including plagiarism, informed consent, misconduct, data fabrication and/or falsification, double publication and/or submission, and redundancies have been completely observed by the authors.

\section{7- References}

[1] Alkan, H., \& Altun, M. (1998). Mathematics teaching”. Eskiúehir, Open Education Faculty Publications.

[2] Daher, W., Sabbah, K., \& Abuzant, M. (2021). Affective engagement of higher education students in an online course. Emerging Science Journal, 5(4), 545-558. doi:10.28991/esj-2021-01296.

[3] Edward A. Silver (1989). NCTM Curriculum and Evaluation Standards for School Mathematics: Responses from the Research Community. Journal for Research in Mathematics Education, 19(4), 338. doi:10.2307/749544. 
[4] Daher, W., \& Baya'a, N. (2012). Characteristics of middle school students learning actions in outdoor mathematical activities with the cellular phone. Teaching Mathematics and Its Applications, 31(3), 133-152. doi:10.1093/teamat/hrr018.

[5] Shahbari, J. A., Daher, W., Baya'a, N., \& Jaber, O. (2020). Prospective teachers' development of meta-cognitive functions in solving mathematical-based programming problems with scratch. Symmetry, 12(9), 1569. doi:10.3390/SYM12091569.

[6] Baya'a, N., \& Daher, W. (2010). Middle school students' learning of mathematics using mobile phones: Conditions and consequences. Journal of Interactive Learning Research, 21(2), 165-185.

[7] Sas, M., Bendixen, L., Crippen, K., \& Saddler, S. (2017). Research and Teaching: Online Collaborative Misconception Mapping Strategy Enhanced Health Science Students' Discussion and Knowledge of Basic Statistical Concepts. Journal of College Science Teaching, 046(06), 88. doi:10.2505/4/jcst17_046_06_88.

[8] Tall, D., \& Vinner, S. (1981). Concept image and concept definition in mathematics with particular reference to limits and continuity. Educational Studies in Mathematics, 12(2), 151-169. doi:10.1007/BF00305619.

[9] Lambertus, A. J. (2007). Students' Understanding of the Function Concept: Concept Images and Concept Definitions. MSc Thesis In Mathematics Education, North Carolina State University, United States.

[10] Vinner, S., \& Dreyfus, T. (2020). Images and Definitions for the Concept of Function. Journal for Research in Mathematics Education, 20(4), 356-366. doi:10.5951/jresematheduc.20.4.0356.

[11] Tall, D. (1992). The Transition to Advanced Mathematical Thinking: In D. Grouws (Ed.), Handbook of Research on MathematicsTeaching and Learning. National Council of Teachers of Mathematics. (pp. 495-511).

[12] Sulastri, R., Suryadi, D., Prabawanto, S., Cahya, E., Siagian, M. D., \& Tamur, M. (2021). Prospective mathematics teachers' concept image on the limit of a function. Journal of Physics: Conference Series, 1882(1). doi:10.1088/1742$6596 / 1882 / 1 / 012068$.

[13] Vinner, S. (2002). The Role of Definitions in the Teaching and Learning of Mathematics. In D. Tall (Ed.), Advanced Mathematical Thinking (pp. 65-81). doi:10.1007/0-306-47203-1_5.

[14] Battista, M. T. (2020). Learning Geometry in a Dynamic Computer Environment. Teaching Children Mathematics, 8(6), 333339. doi:10.5951/tcm.8.6.0333.

[15] Choi-Koh, S. S. (1999). A student's learning of geometry using the computer. Journal of Educational Research, 92(5), 301-311. doi:10.1080/00220679909597611.

[16] Dixon, J. K. (1997). Computer Use and Visualization in Students' Construction of Reflection and Rotation Concepts. School Science and Mathematics, 97(7), 352-358. doi:10.1111/j.1949-8594.1997.tb17376.x.

[17] Lo, J.-J., Gaddis, K., \& Henderson, D. (1996). Building upon Student Experience in a College Geometry Course. For the Learning of Mathematics - An International Journal of Mathematics Education, 16(1), 34-40.

[18] Clements, D. H., \& Battista, M. T. (1992). Geometry and spatial reasoning. In D. Grouws (Ed.), Handbook of research on mathematics teaching and learning: A project of the National Council of Teachers of Mathematics (pp. 420-464). Macmillan Publishing Co, Inc.

[19] Mitchelmore, M. C., \& White, P. (2000). Development of angee concepts by progressive abstraction and generalisation. Educational Studies in Mathematics, 41(3), 209-238. doi:10.1023/A:1003927811079.

[20] Kaur, H. (2020). Introducing the concept of angle to young children in a dynamic geometry environment. International Journal of Mathematical Education in Science and Technology, 51(2), 161-182. doi:10.1080/0020739X.2020.1717657.

[21] Kakihana, K., \& Shimizu, K. (1994). The Roles of Measurement in Proof Problems Analysis of Students' Activities in Geometric Computer Environment. In Proceeding of the 18th Conference of the International Group for the Psychology of Mathematics Education (Vol. 3, pp. 81-88).

[22] Hohenwarter, M., \& Fuchs, K. (2004,). Combination of dynamic geometry, algebra and calculus in the software system GeoGebra. In Computer algebra systems and dynamic geometry systems in mathematics teaching conference (pp. 1-6).

[23] Anabousy, A., Daher, W., Baya'a, N., \& Abu-Naja, M. (2014). Conceiving Function Transformations in Different Representations: Middle School Students Working with Technology. International Electronic Journal of Mathematics Education, 9(2), 97-112. doi:10.29333/iejme/284.

[24] Fahlberg-Stojanovska, L., \& Trifunov, Z. (2010). Constructing and exploring triangles with GeoGebra. Annals. Computer Science Series (Anale. Seria Informatică), 8(2), 45-54.

[25] National Council of Teachers of Mathematics. (2000). Principles and Standards for School Mathematics. In School Science and Mathematics (Vol. 47, Issue 8). NCTM.

[26] Daher, W. (2010). Mathematics Learning Community Flourishes in the Cellular Phone Environment. International Journal of Mobile and Blended Learning, 2(2), 1-17. doi:10.4018/jmbl.2010040101. 
[27] Daher, W. (2014). Students' adoption of social networks as environments for learning and teaching: The case of the facebook. International Journal of Emerging Technologies in Learning, 9(8), 16-24. doi:10.3991/ijet.v9i8.3722.

[28] Baya'a, N., \& Daher, W. (2013). Facebook as an educational environment for mathematics learning. In Ġ. Mallia (Ed.), The Social Classroom: Integrating Social Network Use in Education (pp. 171-190). IGI Global. doi:10.4018/978-1-4666-4904$0 . \operatorname{ch} 009$.

[29] Daher, W. M., \& Shahbari, J. A. (2015). Pre-Service Teachers' Modelling Processes through Engagement With Model Eliciting Activities With a Technological Tool. International Journal of Science and Mathematics Education, 13(1), 25-46. doi:10.1007/s10763-013-9464-2.

[30] Swidan, O., \& Daher, W. M. (2019). Low achieving students' realization of the notion of mathematical equality with an interactive technological artifacts. Eurasia Journal of Mathematics, Science and Technology Education, 15(4). doi:10.29333/ejmste/103073.

[31] NCTM. (2015) "Strategic use of technology in teaching and learning mathematics: A position of the National Council of Teachers of Mathematics", USA.

[32] Parwati, N. N., \& Suharta, I. G. P. (2020). Effectiveness of the implementation of cognitive conflict strategy assisted by e-service learning to reduce students' mathematical misconceptions. International Journal of Emerging Technologies in Learning, 15(11), 102-118. doi:10.3991/IJET.V15I11.11802.

[33] González, G., \& Herbst, P. G. (2009). Students" conceptions of congruency through the use of dynamic geometry software. International Journal of Computers for Mathematical Learning, 14(2), 153-182. doi:10.1007/s10758-009-9152-z.

[34] Biber, Ç, Tuna, A., \& Korkmaz, S. (2013). The Mistakes and the Misconceptions of the Eighth Grade Students on the Subject of Angles. European Journal of science and mathematics education, 1(2), 50-59.

[35] Chazan, D. (1988). Similarity: Exploring the understanding of a geometric concept. (Technical Report No. 88-15). Educational Technology Center, Cambridge, MA.

[36] Gellert, A. (2014). Students discussing mathematics in small-group interactions: opportunities for discursive negotiation processes focused on contentious mathematical issues. ZDM - Mathematics Education, 46(6), 855-869. doi:10.1007/s11858014-0594-y.

[37] Wahyuningtyas, N., \& Idris. (2020). Increasing geographic literacy through the development of computer supported collaborative learning. International Journal of Emerging Technologies in Learning, 15(7), 74-85. doi:10.3991/IJET.V15I07.13255.

[38] Sumtsova, O. V., Aikina, T. Y., Bolsunovskaya, L. M., Phillips, C., Zubkova, O. M., \& Mitchell, P. J. (2018). Collaborative learning at engineering universities: Benefits and challenges. International Journal of Emerging Technologies in Learning, 13(1), 160-177. doi:10.3991/ijet.v13i01.7811.

[39] Herbst, P., Gonzalez, G., \& Macke, M. (2005). How Can Geometry Students Understand What It Means to Define in Mathematics? Mathematics Educator, 15(2), 17-24.

[40] Beňo, M. (2021). The advantages and disadvantages of e-working: An examination using an aldine analysis. Emerging Science Journal, 5(Special issue), 11-20. doi:10.28991/esj-2021-SPER-02.

[41] Daher, W., Anabousy, A., \& Jabarin, R. (2018). Metacognition, positioning and emotions in mathematical activities. International Journal of Research in Education and Science, 4(1), 292-303. doi:10.21890/ijres.383184. 